\title{
BRECHT: A GRANDEZA INTERNA DO STALINISMO
}

\author{
Slavoj Žižek
}

Quando depois da morte de Lênin, o marxismo se dividiu no marxismo soviético oficial e o marxismo chamado ocidental, ambos leram equivocadamente esta externalidade do Partido, considerando-a como a posição do conhecimento objetivo neutro - seguindo os passos de Kautsky, o marxismo soviético adotou simplesmente essa posição, enquanto os marxistas ocidentais a rechaçaram como a legitimação teórica da regra "totalitária” do Partido. Aos poucos os marxistas libertários que quiseram redimir - parcialmente, pelo menos - a Lênin, tenderam a opor ao Lênin jacobino-elitista "mau" do livro $O$ que fazer?, que confiava no Partido como a elite intelectual profissional que ilumina desde fora a classe operária, o Lênin "bom" de O Estado e a Revolução, que teve a visão da abolição do Estado, o das grandes massas que tomam diretamente em suas mãos a administração dos assuntos públicos. No entanto, esta oposição tem seus limites: a premissa chave de $O$ Estado e a Revolução é que não se pode "democratizar" totalmente o Estado, que o Estado "como tal", em sua própria noção, é uma ditadura de uma classe sobre a outra; a conclusão lógica desta premissa é que, na medida em que ainda estamos dentro da lógica do domínio do Estado, estamos legitimados para exercer o terror violento, já que dentro deste domínio, toda democracia é uma fraude. De maneira que, como o Estado é um instrumento de opressão, não vale a pena tratar de melhorar seus aparatos: proteção da ordem legal, eleições, leis que garantam as liberdades pessoais... - tudo isso se torna irrelevante. ${ }^{2}$

O núcleo de verdade destas críticas a Lênin é que a constelação única de acontecimentos que possibilitou a tomada revolucionária do poder em outubro de 1917 não pode ser separada de seu posterior giro "stalinista": a mesma constelação que fez possível a Revolução (o descontentamento dos

${ }^{1}$ Tradução de André Carreira

${ }^{2}$ Uma das estratégias desesperadas para redimir o potencial utópico do Século $X X$ é afirmar que, se 0 Século $X X$ pode gerar um Mal sem precedentes (0 holocausto e o gulag), proporcionou por isto mesmo uma prova negativa de que tal excesso também pode se canalizar na direção oposta, isto é, que o Bem radical é também factível... No entanto, e se está oposição for falsa? E se trata estamos falando de uma identidade mais profunda? E se o Mal radical do Século XX fosse precisamente o resultado dos esforços por realizar 0 Bem radical?

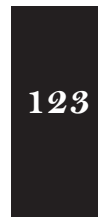




\section{Urdimento}

${ }^{3}$ Georgi Dimitroff, Tagebuercher 19331943, Berlim: Aufbau Verlag 2000.

${ }^{4}$ Um dos poucos historiadores preparados para confrontar esta tensão insuportável é Sheila Fitzpatrick, quem pontuou que 0 ano de 1928 foi um ponto de inflexão crucial, uma verdadeira segunda revolução; não uma espécie de "Thermidor" mas sim uma radicalização conseqüente da Revolução de Outubro. Ver Stalinism. News directions, editado por Sheila Fitzpatrick, Londo: Routledge, 2001. camponeses, uma elite revolucionária bem organizada, etc.) conduziu ao giro "stalinista" como conseqüência - e nisso reside propriamente a tragédia leninista. A famosa alternativa de Rosa de Luxemburgo: "socialismo ou barbárie" terminou com o julgamento infinito último, afirmando a identidade especulativa das duas condições opostas: o socialismo "realmente existente" foi a barbárie.

Nos diários de Georgi Dimitroff, publicados recentemente em alemão ${ }^{3}$, se pode ver que Stalin era totalmente consciente do que o levou ao poder, dando um giro inesperado ao seu conhecido slogan "o povo é nossa maior riqueza". Quando em um jantar em novembro de 1937, Dimitroff comemorava a "grande sorte" dos operários do mundo por terem um líder com a genialidade de Stalin, Stalin respondeu: “... Não estou de acordo. Inclusive se expressou de uma maneira não marxista [ .... $\mathrm{O}$ decisivo são os quadros médios” (7.11.37). Isso fica ainda mais claro um parágrafo antes quando diz: "Por que ganhamos de Trotsky e dos outros? É sabido que, depois de Lênin, Trotsky era o mais popular em nossa terra. [...] Mas nós tivemos o apoio dos quadros médios, e eles explicaram nossa visão da situação às massas... Trotsky não prestou atenção a estes quadros". Aqui Stalin revelou o segredo de sua ascensão ao poder: como Secretário Geral nomeou dezenas de milhares de quadros, que lhe deviam suas promoções... Essa é a razão pela qual Stalin como não queria Lênin morto ainda no início de 1922, rechaçou seu pedido de que o envenenasse acabando com sua vida, depois de ficar debilitado por um ataque cardíaco: se Lênin tivesse morrido no começo de 1922, a questão da sucessão não seria resolvida a favor de Stalin, já que ele como Secretário Geral não havia penetrado ainda no aparato do Partido o suficiente com as pessoas por ele designadas - Stalin necessitava outro ano ou dois para que quando Lênin efetivamente morresse, pudesse contar com o apoio de milhares de quadros de nível médio nomeados por ele, para se impulsionar por cima dos velhos grandes nomes da "aristocracia" bolchevique.

Como conseqüência, já não se pode sustentar o ridículo jogo de se opor o terror stalinista ao "autêntico" legado leninista, traído pelo stalinismo: "Leninismo" é uma noção completamente stalinista. O gesto de projetar o potencial emancipatório utópico do stalinismo para atrás, em um tempo precedente, assinala assim a incapacidade do pensamento para suportar "a contradição absoluta”, a tensão insuportável, inerente ao próprio projeto stalinista 4 . Por tanto, é crucial distinguir o "leninismo" (enquanto núcleo autêntico do stalinismo) da prática política e ideológica fáticas do período de Lênin: a grandeza real de Lênin não é o que diz o mito stalinista sobre o leninismo. E o que responder à contra argumentação evidente de que 
exatamente a mesma coisa vale para cada ideologia, inclusive a do nazismo, que também, percebido desde dentro, apresenta uma "grandeza interna" que seduziu inclusive a um filósofo excelente como Heidegger? A resposta deveria ser simplesmente não é assim: o ponto a sustentar é precisamente que o nazismo não contêm nenhuma "grandeza interna" autêntica.

Se se quer ver a arte stalinista em sua mais pura expressão, um nome é suficiente: Brecht. Badiou tinha razão ao afirmar que

Brecht era um stalinista, sim, como deve-se fazer, se entendo-se o stalinismo como a fusão da política e a filosofia do materialismo dialético sob a jurisdição desta última. Ou precisamente dizer que Brecht praticou um platonismo stalinizado. (1998: 16)

Isto é ao que aponta em última instância o teatro "anti-aristotélico" de Brecht: um teatro Platônico no qual se permite o encanto estético de uma maneira estritamente controlada, para transmitir uma Verdade filosóficopolítica que é externa. O distanciamento (estranhamento) brechtiano significa que "a SEMBLANZA estética tem que se distanciar de si mesma, para que nesta brecha, a objetividade externa do Verdadeiro se mostre ${ }^{5}$. Assim, quando Badiou diz que o "distancimento é um protocolo de vigilância filosófica", ${ }^{5}$ Ibid. ${ }^{6}$ Ibid. deve-se conferir, sem vacilações, a esse termo toda sua dimensão policial. $\mathrm{O}$ jogo ridículo de opor um Brecht "dissidente" ao comunismo stalinista não tem razão de ser: Brecht é o último artista "stalinista", ele não era grande apesar de seu stalinismo, mas sim devido a ele. Realmente necessitamos provas? No final dos anos 30, Brecht comoveu aos convidados de uma festa em Nova York, afirmando sobre um acusado nos Processos de Moscou': "Quanto mais inocente são, mais merecem ser fuzilados"». Esta declaração deve ser tomada muito a sério e não como expressão de um sem vergonha perverso: sua premissa subjacente é que, em uma luta histórica concreta, a atitude de suposta "inocência" ("não quero sujar minhas mãos comprometendo-me na luta, apenas quero levar uma vida modesta e honrada”) encarna a culpa maior. Em nosso mundo, não fazer nada não é algo sem conseqüências, já tem um significado - significa dizer "sim" às relações existentes de dominação. Esse é o porque, a propósito dos processos, Brecht - admitindo que os métodos processamento não eram muito gentis - se fez a pergunta: é possível imaginar que um comunista honrado e sincero, que mantinha suas dúvidas sobre a política de industrialização rápida de Stalin, efetivamente terminara buscando a ajuda dos serviços secretos estrangeiros e se comprometendo em complôs terroristas contra a direção stalinista? Sua resposta foi "Sim”, e propôs uma reconstrução detalhada de seu raciocínio.

${ }^{7}$ Os processos de Moscou foram farsas jurídicas instrumentalizadas por Stalin, nos anos 30, com 0 fim de dizimar a velha guarda do Partido Bolchevique abrindo espaço para a consolidação do seu poder pessoal e para 0 aprofundamento da burocratização do Partido Comunista e do Estado soviético. ${ }^{8}$ Citado por Sidney Hook, Out of Step, New York: Dell, 1987, p.493.

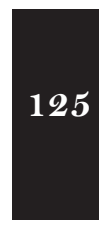




\section{Urdimento}

${ }^{9}$ Ver Carola Stern, Maenner lieben anders. Helene Weigel und Bertolt Brecht, Reinebek Hamburg: Rowohlt 2001, p. 179.

${ }^{10}$ Bertolt Brecht, Gesammelte Werke, Ata 20, Frankfort: Suhrkamp Verlag, 1967, p. 327.

${ }^{11}$ The Cambridge Companion to Brecht, edited by Peter Thomson, Cambridge: Cambridge University Press 1994, p. 162.

${ }^{12}$ Ver Bertolt Brecht, Ueber die Diktaturen eizelner Menschen, em Schriften, vol. 2. Frankfurt: Suhrkamp Verlag 1973, p. 300301.

${ }^{13}$ Bertolt Brecht, Gesammelte Werke, Ata 20, p. 326.

Não surpreende então que, quando no caminho de sua casa ao teatro em julho de 1956, Brecht passou ao lado de uma coluna de tanques soviéticos que rodavam para o Stalinalee para reprimir uma rebelião de trabalhadores, os saudou com a mão e mais tarde neste dia escreveu em seu diário que, neste momento, por primeira vez em sua vida (não havendo sido nunca membro do Partido) esteve tentado a se inscrever no Partido Comunista ${ }^{9}$ - não é este um caso exemplar do que Alain Badiou chamou la pasion du reel, que define o Século XX? Não é que Brecht tolerasse a crueldade da luta com a esperança de que esta trouxesse um futuro próspero: a crueza da violência presente como tal era percebida e advogada como signo de autenticidade. Para Brecht, a intervenção militar soviética contra os operários de Berlim Oriental não apontou aos operários, mas sim aos "elementos facistas organizados" que se aproveitam do descontentamento dos operários; por essa razão, ele afirmou que a intervenção soviética efetivamente preveniu uma nova guerra mundial ${ }^{10}$. Inclusive no nível pessoal Brecht "realmente gostava de Stalin"1l, e desenvolveu uma linha de argumentação que justificava a necessidade revolucionária da ditadura de um só indivíduo ${ }^{12}$; sua reação à "desestalinização" do XX Congresso do Partido Comunista Soviético de 1956 foi: "Sem o conhecimento da dialética, a passagem de Stalin como motora Stalin como obstáculo não pode ser entendida"13. Em resumo,: no lugar de denunciar Stalin, Brecht jogou o jogo do pseudo-dialético do "o que era antes, nos anos 30, progressista, agora (nos anos 50) se converteu em obstáculo...”. Quase estaríamos tentados a ler o momento da morte de Brecht (outono de 1956, justo depois do XX Congresso do PCUS e antes do levantamento húngaro) como oportuno: a misericórdia da morte o impediu ter que confrontar toda a dor da "desestalinização".

Se queremos compreender verdadeiramente a Brecht, devemos estudar a grande troika musical alemã stalinista: Brecht (letra), Hanns Eisler (música), Ernest Busch (execução). Para se convencer da grandeza autêntica do projeto stalinista, basta escutar uma das gravações supremas do Século XX, as Gravações Históricas de Hanns Eisler (Clássicos de Berlim, LC 6203), com (a maioria de) letras de Brecht e (a maioria) das canções executadas por Busch. No que talvez seja sua conquista suprema, a canção Im Gerfaengris zu sigen de Die Mutter, se faz alusão diretamente à brecha entre a decomposição simbólica do oponente e sua derrota real, quando o operário Pavel preso se dirige aos que estão no poder:

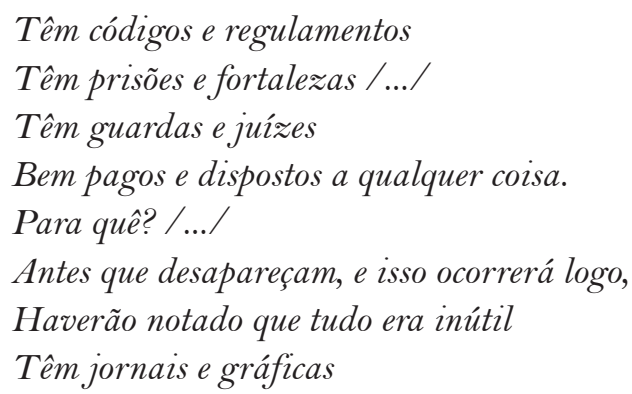


Para nos combater e nos manter quietos /.../

Têm sacerdotes e professores

Bem pagos e dispostos a qualquer coisa.

Para quê?

Realmente têm tanto medo da verdade?

Têm tanques e fuzis

Armas Tommy e granadas de mão /.../

Têm policiais e soldados

Para quê?

Realmente têm inimigos tão poderosos? /.../

Algum dia, e esse dia virá logo,

Verão que tudo não lhes serviu de nada ${ }^{14}$

A derrota real do inimigo é precedida por sua decomposição simbólica, pela súbita visão de que a luta não tem sentido, e todas as armas e ferramentas à sua disposição não servem de nada. Nisto reside a aposta principal da luta política: por razões estruturais a priori e não somente devido a algum cálculo errôneo contingente, o inimigo percebe erradamente as coordenadas da situação global e reúne as forças equivocadas no lugar equivocado. Dois recentes exemplos: a que apontava o aparato repressivo do Xá do Irã em 1979 quando se enfrentou com o movimento popular de Khomeini? Simplesmente se derrubou. E de que serviu a grande rede de agentes e informantes Stasi para a nomenklatura comunista da Alemanha Oriental em 1989, quando se enfrentou com os protestos massivos? Os grandes regimes opressivos nunca são derrotados em uma confrontação face a face - em certo ponto, quando o "velho verme" completa seu trabalho subterrâneo se derrubam. - Além da sublime obra prima: "Elogio do Comunismo" ("a mais simples, que é a mais difícil de se conseguir”), a terceira canção mais importante de $A$ Mãe é $A$ canção do remendo e do vestido, que começa com um retrato irônico dos filantropos que têm urgência de ajudar aos pobres:

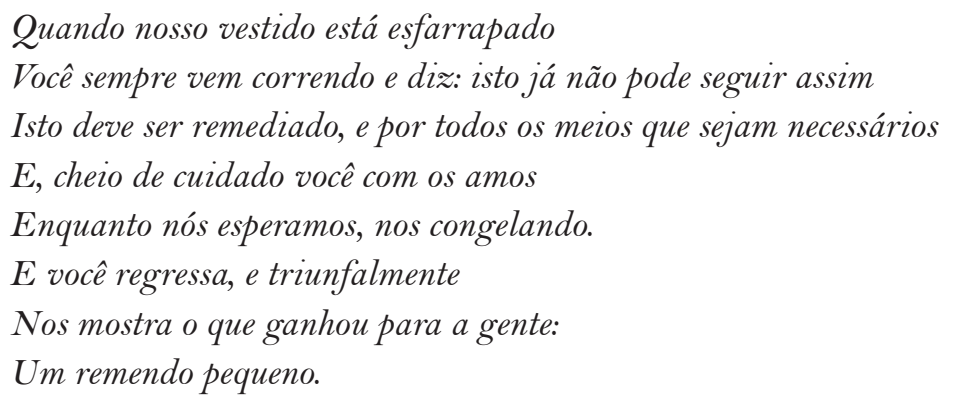

\footnotetext{
${ }^{14}$ Bertolt Brecht, Die Mutter, Frankfort: Suhrkamp 1980. p. 47-48.
} 


\section{Urdimento}

${ }^{15}$ Ibid, p.21-22

${ }^{16}$ Como é usual, Brecht toma emprestado aqui de uma canção anterior de Busch, a Balada da Caridade, composta por Eisler em 1930, com letra de Kurt Tucholsky; o estribilho da canção dizia: "Gut, das ist der Pfennig, und wo ist die Mark?".

\section{Está bem, esse é nosso remendo}

Mas, onde está

$O$ vestido inteiro? ${ }^{15}$

Depois de que está pergunta retórica se repete a propósito do pão ("está bem, isso é uma fatia de pão, mas onde está o pão inteiro"16), a canção acaba em uma explosão gigante de demandas (“...necessitamos a fábrica inteira, e o carvão e o ferro e o poder do Estado”) - o momento propriamente revolucionário no qual o quid pro quo de intercâmbios com os que estão no poder se rompe, e os revolucionários afirmam brutalmente que eles querem tudo, não somente uma "mera" parte... Brecht está aqui nas antípodas de Georg Lukacs, precisamente na medida em que Lukacs, o humanista europeu "brando", jogou o papel de "dissidente de armário", empreendendo uma "guerra de guerrilhas" contra o stalinismo, inclusive unindo-se ao governo de Imre Nagy em 1956, pondo em perigo sua existência física. Em contraste com Lukacs, Brecht foi insuportável para o establishment cultural stalinista precisamente devido a sua "super-ortodoxia" - não há nenhum lugar para A Medida Tomada no universo cultural do stalinismo. Se o jovem Lukacs de História e Consciência de Classe foi o filósofo do momento histórico de Lênin, depois dos anos 30 se converteu no filósofo stalinista ideal que, por essa mesma razão, em contraste com Brecht, se perdeu a verdadeira grandeza do stalinismo. 